\title{
Multiscale Modeling of Composites: Toward Virtual Testing ... and Beyond
}

\author{
J. LLORCA,${ }^{1,2,3}$ C. GONZÁLEZ, ${ }^{1,2}$ J. M. MOLINA-ALDAREGUÍA, ${ }^{1}$ \\ and C. S. LOPES ${ }^{1}$
}

\begin{abstract}
Recent developments in the area of multiscale modeling of fiber-reinforced polymers are presented. The overall strategy takes advantage of the separation of length scales between different entities (ply, laminate, and component) found in composite structures. This allows us to carry out multiscale modeling by computing the properties of one entity (e.g., individual plies) at the relevant length scale, homogenizing the results into a constitutive model, and passing this information to the next length scale to determine the mechanical behavior of the larger entity (e.g., laminate). As a result, high-fidelity numerical simulations of the mechanical behavior of composite coupons and small components are nowadays feasible starting from the matrix, fiber, and interface properties and spatial distribution. Finally, the roadmap is outlined for extending the current strategy to include functional properties and processing into the simulation scheme.
\end{abstract}

\section{INTRODUCTION}

Fiber-reinforced polymers (FRP) stand out among structural materials because of their unique combination of properties. The reinforcement with highperformance fibers provides a stiffness and strength comparable to those of metallic alloys, the structural materials par excellence, and very often higher if the comparison is carried out in terms of specific properties Fig. 1a. In addition, structural composites can dissipate a large amount of energy upon fracture (in the range $\approx 10-50 \mathrm{~kJ} / \mathrm{m}^{2}$ ), leading to a flaw-insensitive, damage-tolerant behavior that is not prone to catastrophic failure (Fig. 1b). This combination of stiffness, strength, and toughness is only found in human-made metallic alloys, in which stiffness comes from the strong metallic bonding, whereas energy dissipation during fracture is ensured by plastic deformation and different strategies (alloying, second-phase precipitation, and grain-size reduction) can be used to increase strength while maintaining acceptable toughness values. Polymers and rubbers can also dissipate large amounts of energy during deformation, but their strength and stiffness are limited, whereas ceramics are stiff and strong but brittle, as a result of their ionic or covalent bonding, which hinders dislocation motion.

The combination of high specific stiffness and strength as well as toughness in the absence of plastic deformation can also be found in structural biomaterials, ${ }^{1}$ such as tendons, ${ }^{2}$ bones, ${ }^{3}$ seashell nacre, ${ }^{4}$ and spider silk. ${ }^{5}$ In all cases, the superior mechanical properties of these materials in terms of stiffness, strength, and particularly, of toughness can be traced to their hierarchical microstructure, which leads to the simultaneous activation of different deformation and energy dissipation mechanics at length scales from $\mathrm{nm}$ to the component level, dramatically enhancing the damage resistance. ${ }^{6}$ The analysis of the micromechanisms of deformation in FRP has also led to the conclusion that their excellent mechanical properties come about as the result of a simple-but efficient-hierarchical structure, which produces tough materials from brittle constituents. ${ }^{7}$

Structural components made up from FRP are made up of laminates that in turn are obtained by stacking individual plies with different fiber orientation. This leads to three different entities (ply, laminate, and component) with three different characteristic length scales (fiber diameter, ply, and 


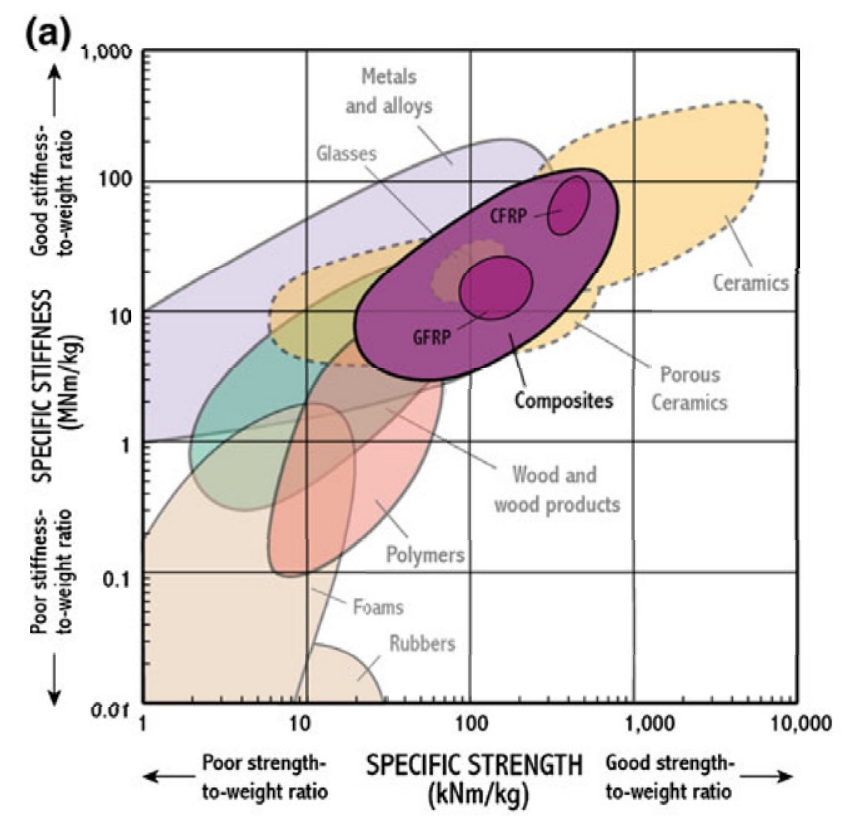

(b)

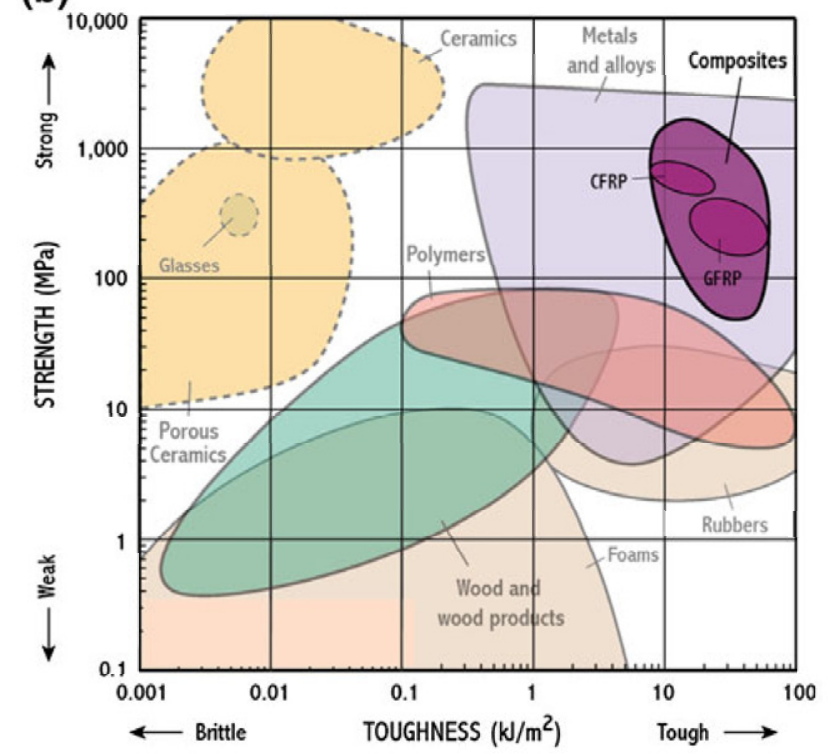

Fig. 1. Comparison of the mechanical properties of composites with other materials. (a) Specific stiffness versus specific strength and (b) strength versus fracture toughness. CFRP, carbon-fiber reinforced polymers; GFRP, glass-fiber reinforced polymers.

laminate thickness, respectively) arranged in a hierarchical fashion (Fig. 2). Carbon fiber diameters are of the order of 5-10 $\mu \mathrm{m}$, whereas ply thicknesses are in the range $100-300 \mu \mathrm{m}$, and standard laminates are several $\mathrm{mm}$ in thickness and greater. Upon mechanical loading, different deformation and failure mechanisms take place simultaneously at the three length scales depicted in Fig. 2. Within each ply, the main damage mechanisms depend on the load orientation with respect to the fibers. If the ply is subjected to tensile stresses perpendicular to the fibers, then matrix failure leads to the formation of a crack perpendicular to the tensile axis (Fig. 3a), whereas if the ply is loaded in compression perpendicular to the fibers, then final failure occurs by formation of a shear band of localized plastic deformation in the matrix across the ply (Fig. 3b). ${ }^{9}$ Tensile loading parallel to the fibers leads to brittle fracture controlled by the fibers, whereas a compression along the fibers induces failure by fiber kinking. ${ }^{10}$ These failure modes control the mechanical behavior of unidirectional plies, but other energy-dissipation mechanisms develop during deformation of multidirectional laminates made up by stacking unidirectional plies in different orientations. They include multiple cracking of the plies parallel to the fibers, as well as fiber bridging, followed by fiber fracture and pull out (Fig. 4), dramatically increasing the energy dissipated during fracture of multidirectional laminates. In addition, interply decohesion often develops from the laminate edges as a result of the stress concentration caused by the mismatch in the elastic properties of adjacent plies or from the bifurcation along the interply of intraply cracks. Finally, other mechanisms associated with the structural deformation of the component (buckling, crushing, and large deformations) also contribute to the total energy absorption of composite structures.

Obviously, the presence of different energy dissipation mechanics at various length scales calls for a multiscale modeling strategy. Although this challenge was clear to scientists and engineers, ${ }^{12}$ it was only very recently that a coherent multiscale approach to carrying out high-fidelity simulations of the mechanical performance of composite laminates was proposed and validated. ${ }^{7}$ This new strategy comes about as a result of recent advances in different areas, including micromechanical characterization of constituent properties, development of accurate modeling tools for composites at the microscale and mesoscale, coherent strategies to pass information between length scales, and the use of parallelization techniques to increase the power of digital computers. As a result, "virtual tests" are starting to be used in engineering applications to limit the number of costly experimental tests to certify the safety of composite structures, and to reduce development time. In addition, this strategy makes structural design with nonconventional laminates possible, as well as their optimization under nontrivial load cases such as impact. The main features of this new multiscale modeling strategy are presented in this article together with insights into the future directions of the integrated computational engineering of multifunctional composites.

\section{MULTISCALE MODELING OF STRUCTURAL COMPOSITES}

Multiscale modeling of structural composites has been attempted in the past using the global-to-local approach. In this methodology, the mechanical 
performance of the whole structure is analyzed (normally using the finite-element method) to identify the critical regions in which damage is likely to develop. These regions are subjected to refined analyses using phenomenological models for the composite behavior that include damage. These models contain a number of parameters whose values are chosen to reproduce the actual material behavior as a result of experience and costly testing campaigns. ${ }^{13}$ Although this strategy has proven very useful from the structural engineering view- point, the phenomenological nature of the composite material models limits its ability to extend the results to design optimized lay-up configurations or to carry out "virtual tests" on structural components that present very different damage mechanisms upon loading.

As opposed to this strategy, a new approach that follows the hierarchical structure of composite materials has been proposed and validated. ${ }^{7}$ The overall multiscale simulation scheme is depicted in Fig. 5 and takes advantage of the natural separa- (a) ply

fiber diameter

$\approx 10 \mu \mathrm{m}$

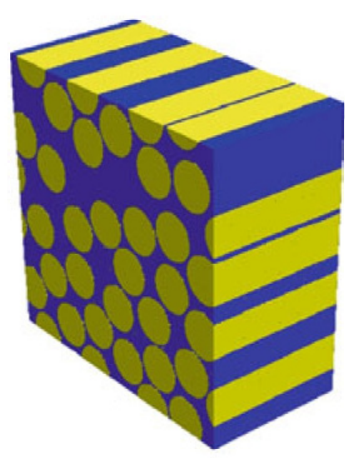

matrix shear yielding interface decohesion fiber fracture fiber kinking (b) Laminate

ply thickness

150-300 $\mu \mathrm{m}$

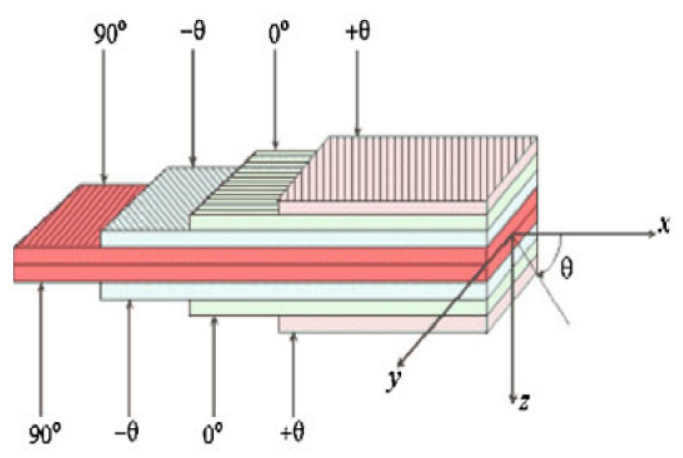

crack bridging

fiber pull-out

matrix cracking

interply decohesion (c) Component

laminate thickness 2-20 mm

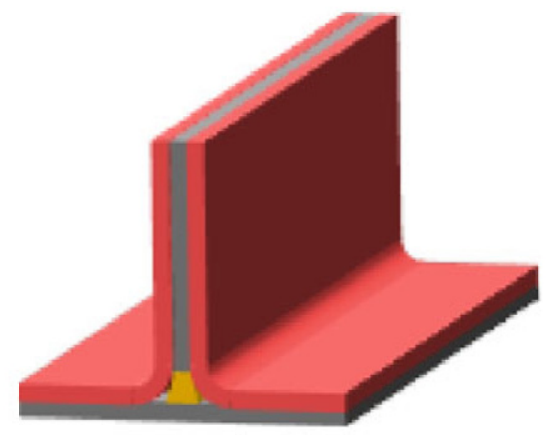

buckling

crushing

Fig. 2. Hierarchical structure of composite materials, showing the three entities, their relevant length scale and their dominant energy dissipation mechanisms. (a) ply, (b) laminate, and (c) component.
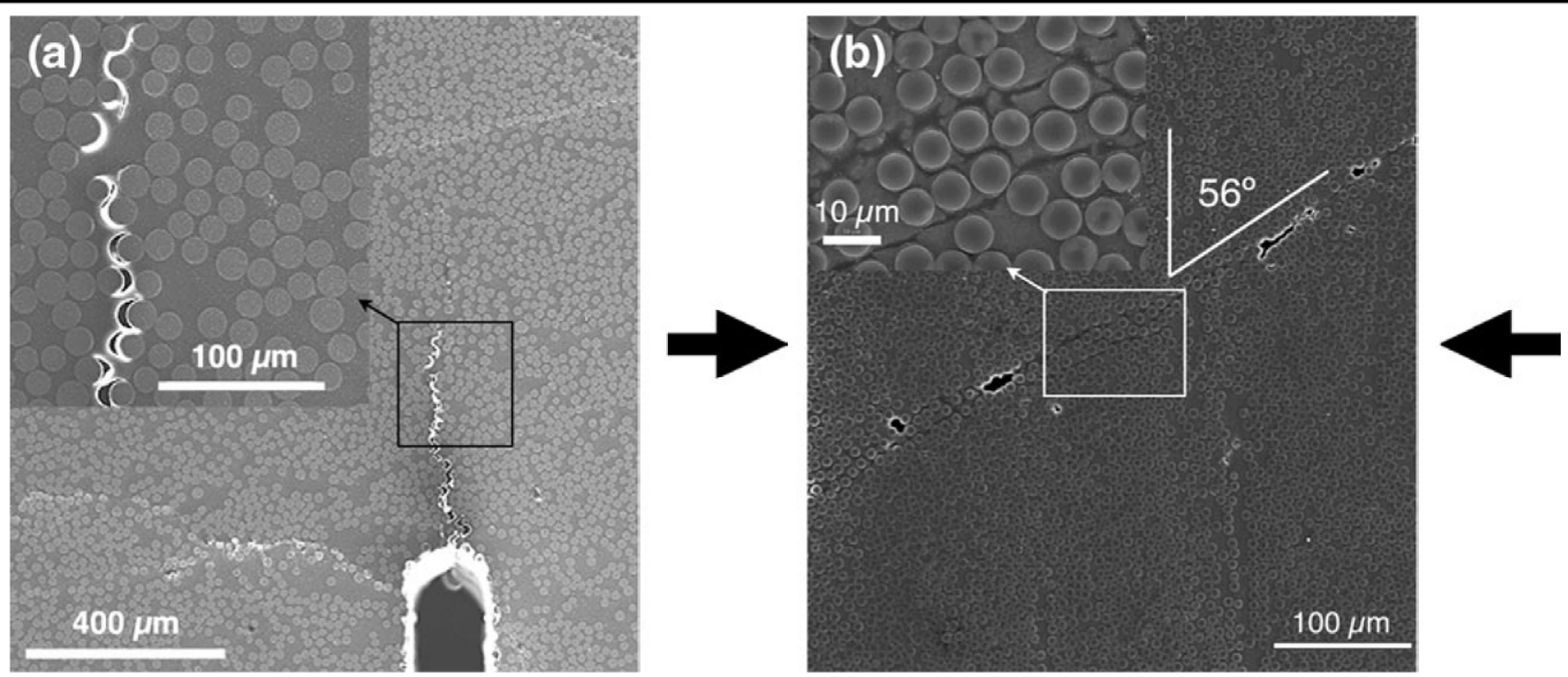

Fig. 3. Scanning electron microscopy of ply damage by loading perpendicular to the fibers. (a) Tensile damage by interface decohesion and matrix fracture at the notch root in epoxy/glass FRP. ${ }^{8}$ (b) Compressive damage by the formation of plastic shear band in the matrix in an epoxy/C FRP $^{9}$. 


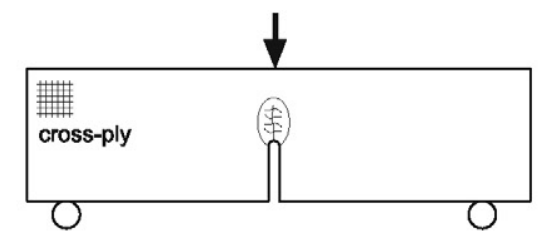

(a)

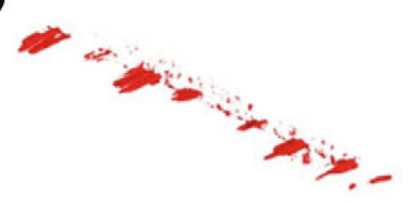

$0.2 \mathrm{kN}$ (b)

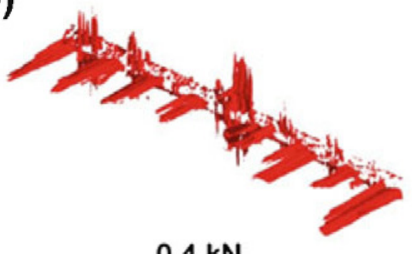

(c)

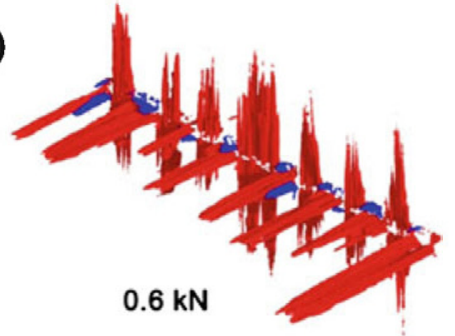

(d)

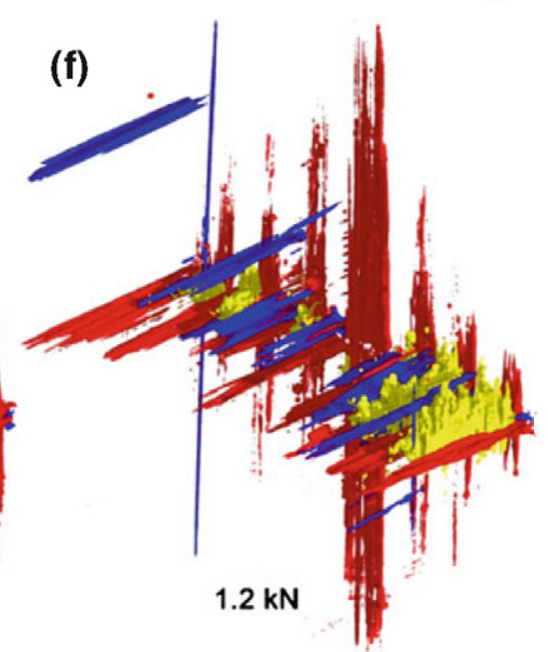

$0.8 \mathrm{kN}$

(e)

$1.0 \mathrm{kN}$

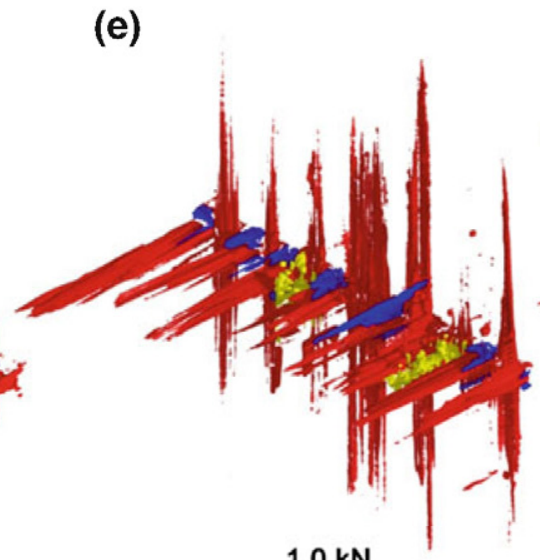

(n)

Fig. 4. Development of damage at the notch root as a function of the applied load in a cross-ply epoxy/glass [0/90] $4 \mathrm{~s}$ laminate. Damage began by the nucleation of intraply cracks in the $90^{\circ}$ plies (fibers contained in the notch plane) shown in red in (a). Upon further loading, intraply cracking begins in the $0^{\circ}$ plies (b) and then by the formation of secondary cracks in the $90^{\circ}$ plies, shown in blue in (c), (d), (e), and (f). The number and length of the intraply cracks increased with the applied load and fiber fracture and fiber bridging (in yellow) developed in the external $0^{\circ}$ plies when the applied load reached $1 \mathrm{kN}$. The maximum load carried by the notched beam was $1.56 \mathrm{kN}$. Adapted from Ref. ${ }^{11}$ (Color figure online).

tion of length scales between different entities (ply, laminate, and component) found in composite structures. This allows multiscale modeling to be carried out by computing the properties of one entity (e.g., individual plies) at the relevant length scale, homogenizing the results into a constitutive model, and passing this information to the next length scale to determine the mechanical behavior of the larger entity (e.g., laminate). Thus, multiscale modeling is carried out through the transfer of information between the three different length scales rather than by coupling different simulation techniques. The relevant features of each step are detailed below.

\section{Computational Micromechanics}

Computational micromechanics, the first step in this multiscale modeling approach, is used to predict the ply properties from the thermomechanical properties of the constituents (fiber, matrix, and interfaces), together with the volume fraction and spatial distribution of the fibers within an individual ply. Fiber properties (stiffness, strength, and coefficients of thermal expansion) are normally provided by the fiber manufacturer. Matrix and interface properties depend, however, on the consolidation process (time, pressure and temperature, and effect of fiber dispersion), and they have to be characterized in situ by means of nanomechanics. It was recently shown that the most relevant matrix mechanical properties (elastic modulus, flow stress, and pressure sensitivity of the flow stress) can be obtained by means of nanoindentation tests in matrix pockets within the plies. ${ }^{14}$ Similarly, push-in tests on individual fibers carried out with a nanoindenter can be used to measure the matrix/fiber interface properties in situ. ${ }^{15,16}$

The mechanical response of the ply is obtained by means of the finite-element analysis of a representative volume element (RVE) of the ply microstructure. It was demonstrated ${ }^{9}$ that a periodic RVE 
containing a random dispersion of a few dozen fibers is enough to accurately reproduce the ply behavior under general loading conditions in the standard case unidirectional reinforcement. The main deformation and damage mechanism experimentally observed in the constituents are introduced in the simulations with interface elements (to model interface decohesion) or the appropriate constitutive models to take into account the plastic deformation and fracture of matrix and fibers. This strategy has been successfully used to predict the failure locus of unidirectional plies subjected to various in-plane and out-of-plane loading conditions. ${ }^{17-24}$ Finally, computational micromechanics can also be used to determine the fracture resistance of a ply, ${ }^{8,25}$ although the modeling strategy is slightly different because damage is localized and propagates from the tip of a sharp notch (Fig. 3a). The simulations are carried out within the framework of an embedded cell model (Fig. 6a) in which the full details of the composite microstructure are resolved in the fracture region. The remaining ply material is represented as a homogeneous, transversally isotropic solid whose behavior is given by any suitable homogenization model. Of course, matrix fracture and interface decohesion are included in the corresponding constitutive equations in the embedded region, and this leads to the development of damage in front of the notch tip upon loading (Fig. 6b). The crack propagation from the notch accurately reproduces the experimental crack path, which is shown in Fig. 3a. From the macroscopic load-displacement curve of this "virtual" fracture test (Fig. 6c), it is possible to determine the ply toughness (as well as the increase in fracture resistance with crack length) using the standard expressions available in the fracture mechanics textbooks.

\section{Computational Mesomechanics}

Computational mesomechanics, the second step in the multiscale modeling strategy, also uses the finite-element method to determine the mechanical response of laminates (Fig. 5). The virtual laminate is built by stacking plies with different fiber orientation $(\theta)$, and the geometrical model explicitly includes each ply as well as the interfaces between plies (Fig. 7a). Meshing of the laminate is carried out with solid elements for the plies, while cohesive interface elements (or cohesive surfaces) are used to take into account the ply interfaces. In this way, intraply and interply damage can be introduced separately together with the complex interaction between them.

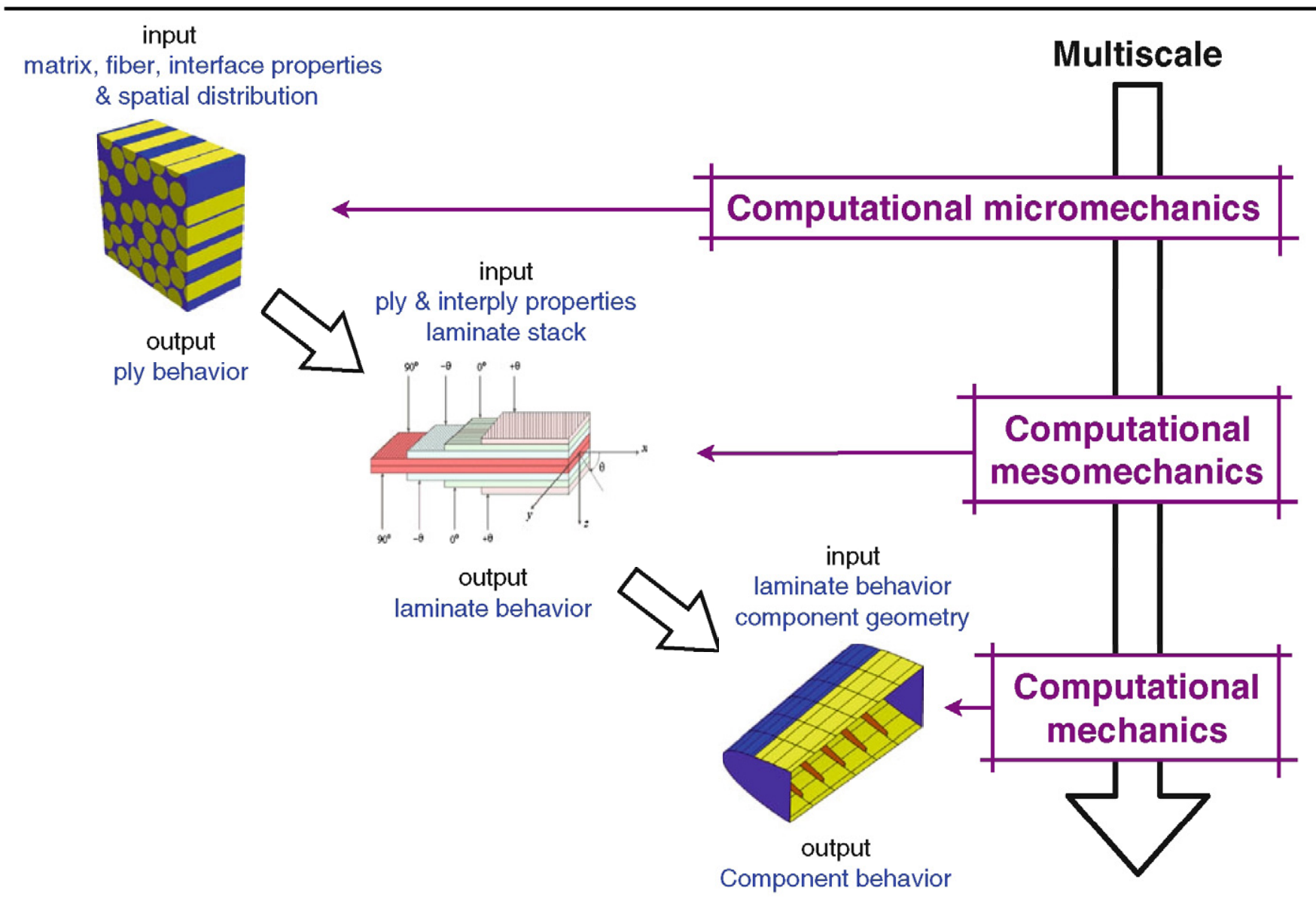

Fig. 5. Local-to-global multiscale simulation strategy to carry out virtual mechanical tests of composite materials. 

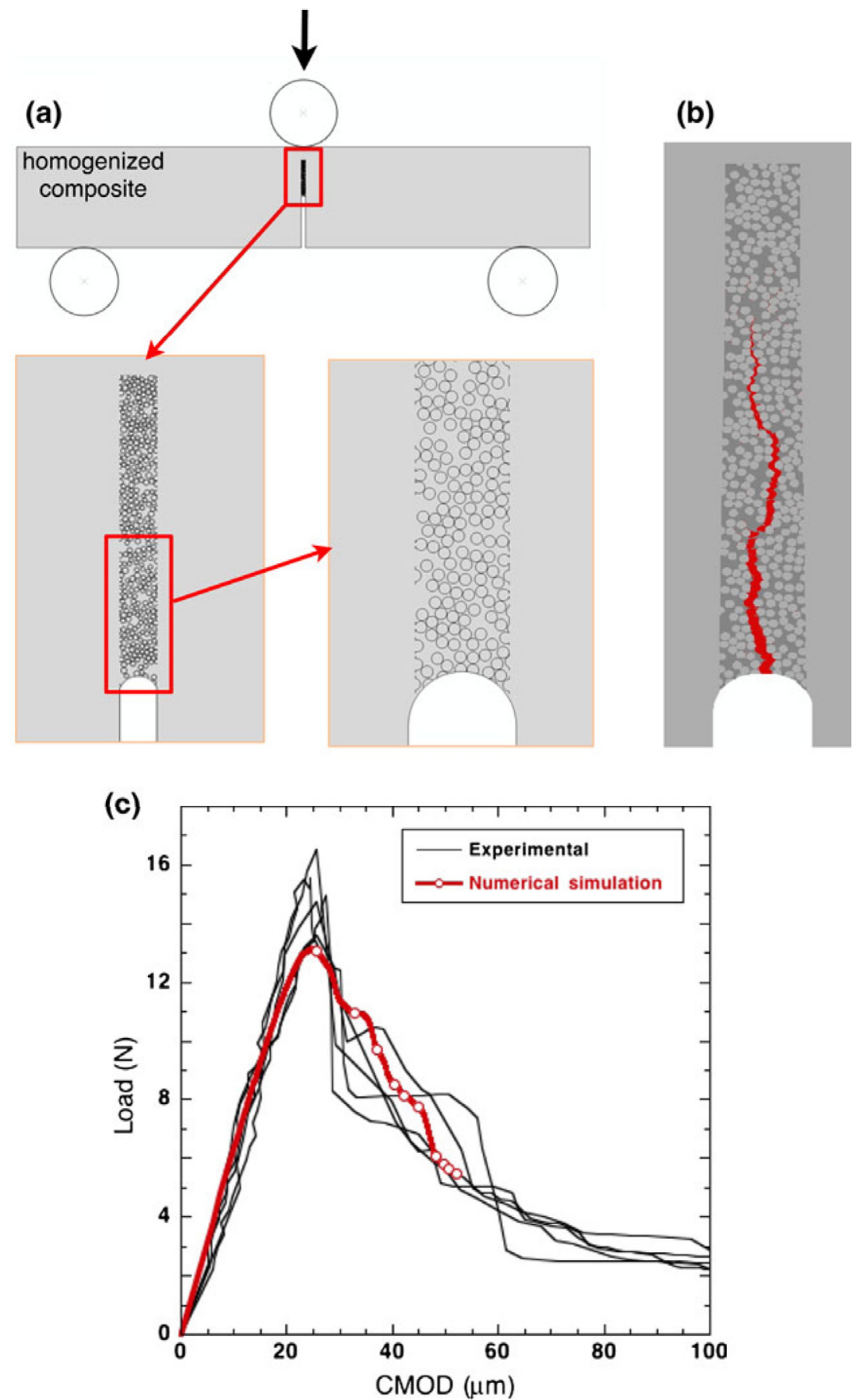

Fig. 6. (a) Embedded cell strategy to determine the fracture resistance of a uniaxially reinforced ply. The details of the microstructure (fibers and matrix) are resolved in the notch front, while the remaining solid is represented by a homogeneous, transversally isotropic solid. (b) Detail of the propagation of the crack through the microstructure from the notch tip to be compared with experimental observations in Fig. 3a. (c) Experimental and numerical results of the load-crack mouth opening displacement curves for the three-point bend tests on notched beams. Adapted from Ref. ${ }^{8}$.

Damage by interply decohesion in these models is included by means of a cohesive crack model coupled with interface elements between the ply surfaces $^{26}$ following a similar approach to that used to simulate decohesion at the fiber-matrix interface in computational micromechanics. ${ }^{18-24,27}$ The interply properties (normal and shear interply strength as well as mode I and mode II fracture toughness) can be obtained from standard mechanical tests. ${ }^{28}$

Intraply damage is more difficult to simulate as the plies are modeled as transversally isotropic, homogeneous solids, but different physical damage modes develop as a function of loading orientation and sign. The elastic ply properties are easily 


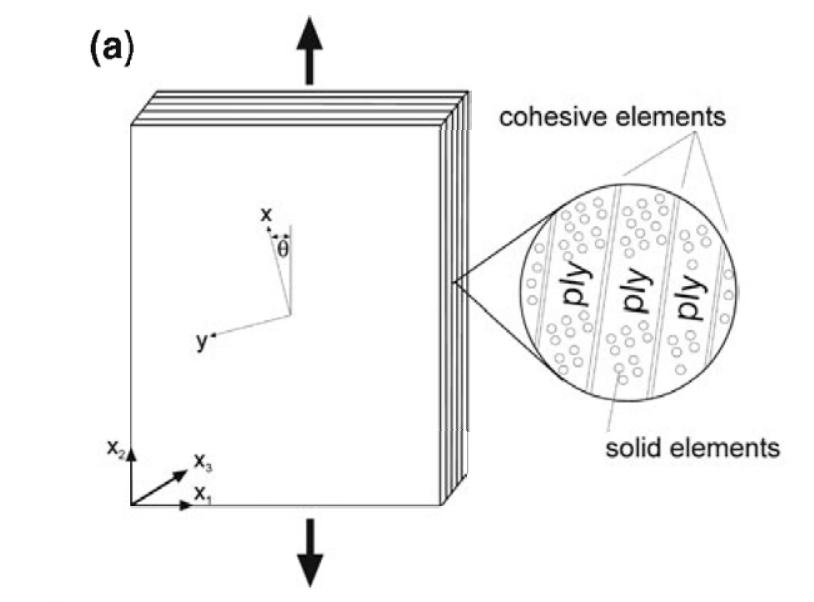

(b)
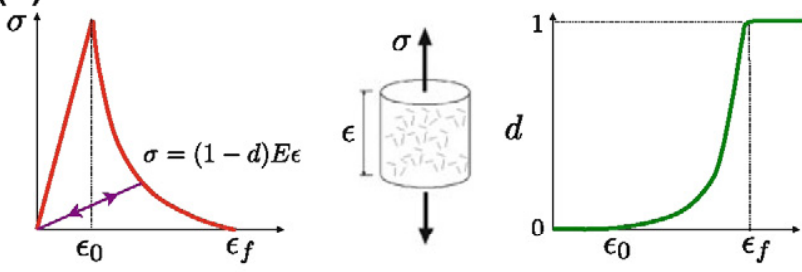

Fig. 7. (a) Schematic of computational mesomechanics approach to simulating the behavior of composite laminates. (b) Stress-strain curve and damage evolution law for a linear isotropic material loaded in tension according to CDM.

obtained from the fiber and matrix elastic constants and volume fraction from standard homogenization models. The onset of damage is predicted by the failure surface, which can be obtained from numerical simulations based on computational micromechanics. ${ }^{17-24}$ (as described in the previous section) or from experimentally validated phenomenological models. ${ }^{29-32}$ In this way, the combination of stresses that leads to the initiation of damage and the particular damage mode activated (matrix cracking, fiber kinking, etc.) is known. Nevertheless, laminate failure is not always associated with the initiation of damage and the accurate prediction of the maximum load-bearing capacity requires computing the evolution of damage, including the interaction among the different physical failure modes. This is a very complex problem, and successful, accurate results were obtained through the application of different approaches based on discrete cracks and continuum damage mechanics (CDM). In both cases, the onset of damage is dictated by the failure surface, while the fracture energy associated to the cohesive crack, which controls the propagation of the crack or damage can be obtained by means of computational micromechanics (Ref. ${ }^{8}$ and Fig. 6) or from mechanical tests. ${ }^{33,34}$

Intraply damage under tensile and shear stresses normally begins by the propagation of cracks parallel to the fibers, and this failure mode can be accounted for by means of interface elements inserted a priori along the fiber direction ${ }^{35-38}$ or, more recently, with the eXtended- Finite Element Method (X-FEM) techniques. ${ }^{39,40}$ This strategy has been successfully applied to modeling the behavior of laminates with a notch or a central hole under tension, ${ }^{35-38}$ including the influence of stacking sequence, ply thickness, and specimen size on the maximum load and the sequence of deformation and failure mechanisms.

The most popular strategy to capture all the intraply failure mechanisms within a single framework is provided by the formalism of CDM. Within this framework, damage is assumed to develop by the formation of a homogeneous distribution of microcracks and is characterized by a damage variable $d$, which stands for the areal density of microcracks. In the case of a linear and isotropic material loaded in tension, the constitutive behavior can be expressed mathematically as a function of $d$ as (Fig. 7b)

$$
\sigma=[1-d(\varepsilon)] E \varepsilon
$$

where $E$ is the elastic modulus of the undamaged material. The response of the material is initially elastic up to a strain $\varepsilon_{0}(d=0)$, at which damage starts to grow until complete fracture occurs at $\varepsilon_{f}(d=1)$. The damage variable controls the evolution of damage and may depend on any internal variable (such as stress, strain, elastic energy, etc.), and the area under the stress-strain curve is the energy spent during failure per unit of volume. This basic framework has been extended by different authors to model the mechanical performance of an orthotropic ply taking into account the different intraply failure mechanisms. ${ }^{41-43}$ Continuum damage models have been implemented in either implicit or explicit finite element codes, and in combination with interface elements to simulate interply decohesion, they have been used to simulate the size effects in notched laminates loaded in tension, ${ }^{33}$ the compressive strength of variablestiffness panels, ${ }^{44}$ and the mechanical behavior of laminates under impact. ${ }^{7,45-47}$

These techniques have matured in recent years, and the optimization of composite laminates by means of virtual testing is becoming real. Due to the lack of reliable analytical models, one issue that is often overlooked in the optimization of composites is low-velocity impact resistance and damage tolerance. Instead, the selection of laminates is based on limited experimental testing on promising configurations that show optimal performance in terms of other structural requirements, such as stiffness and buckling. This highly constrains the design possibilities since the experimental evaluation of a large amount of specimens is very costly.

With the current state of the art, virtual testing tools based on CDM can be coupled with multiobjective optimization schemes based on evolutionary algorithms, such as genetic algorithms or ant colony optimization, to design composite laminates with 


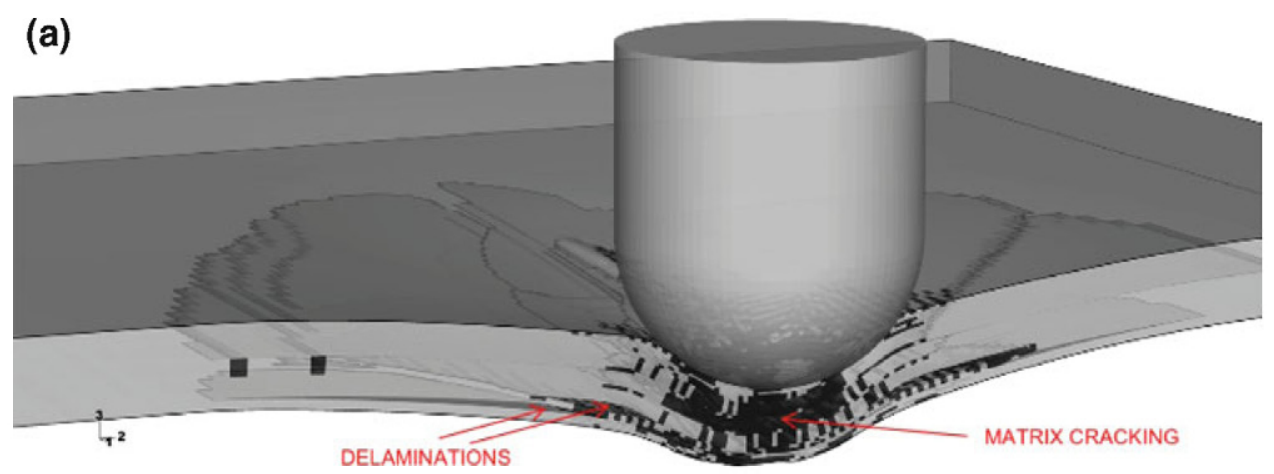

(b)
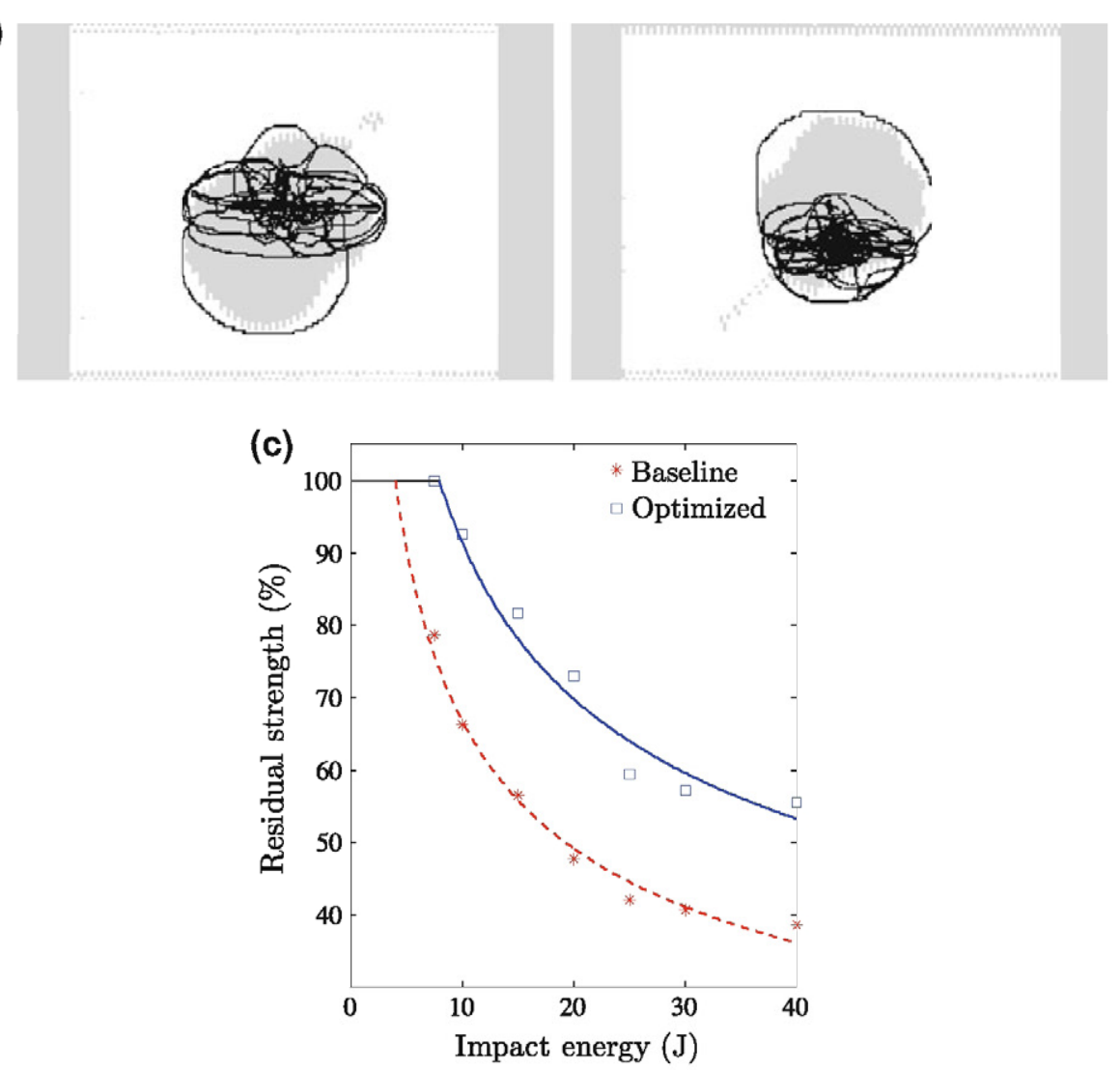

Fig. 8. Optimization of composites laminates with virtual testing. (a) Virtual impact test $(20 \mathrm{~J})$ on a standard coupon showing matrix cracks and delaminations. (b) Impact footprint (superposition of damage at all layers and interfaces) on a traditional laminate (left) and on an optimized configuration (right). The gray areas are the $\mathrm{C}$-scan measurements, whereas the visible dark lines correspond to the numerical prediction of the extent of delaminations at each interface. (c) Normalized residual strength results obtained with compression-after-impact tests.

optimal impact resistance and damage tolerance, in addition to stiffness and buckling. ${ }^{48,49}$ In laminates optimized in such a way, the stacking sequences may be dispersed in the $0-90^{\circ}$ range in order to mitigate the occurrence of matrix cracks in plies that would otherwise be clustered at the same orientation, or to alleviate interlaminar stresses and increase interface fracture resistance. Thus, the number and extent of delaminations is decreased and the reduction of the residual strength of laminate is limited, i.e., improving its damage tolerance. An example of the results achieved by this multiobjective optimization process based on virtual testing is illustrated in Fig. 8 as well as its experimental validation. ${ }^{48,49}$

\section{Computational Mechanies}

Computational mesomechanics simulations are limited to composite coupons or small panels, and they cannot be extended to structural components due to the associated computational cost. Thus, computational mechanics simulation of the composite structures is the last step in the multiscale simulation strategy (Fig. 5) and the one that still needs the development of a robust methodology to bridge the length scales. 
In this approach, the laminate is modeled by means of shell elements, which contain as many integration points through the thickness as the number of plies in the laminate in each region of the component, but different plies are not modeled independently (Fig. 9). Thus, the analyses are limited to bidimensional stress states at the lamina

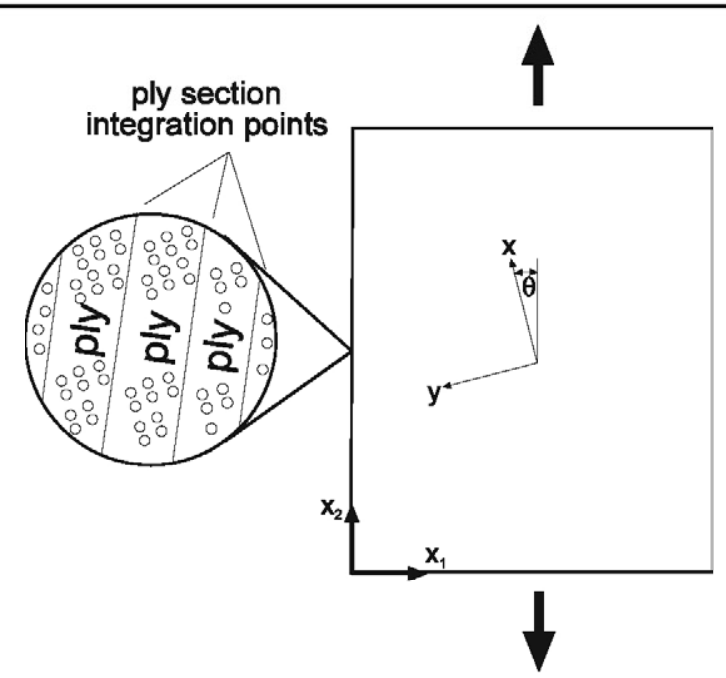

Fig. 9. Schematic of computational mechanics approach for composite structures. level but are very efficient from the numerical viewpoint and can capture the structural failure modes of large structures (buckling and large deformations). However, it is necessary to include accurate models for the onset and evolution of damage at the laminate level in order to ensure the fidelity of the numerical simulations. This can be achieved by treating the laminate as a homogeneous material whose mechanical behavior until fracture is dictated by CDM. The stiffness constants of the laminate are easily obtained using laminate theory while the onset of damage is provided by a failure locus in the stress space. The failure locus as well as the evolution of damage during deformation can be obtained by computational mesomechanics simulations of the laminate under uniaxial and multiaxial stress states under different loading conditions (tension and compression in perpendicular directions, shear as well as multiaxial loading). This information is used as input for the damage evolution laws of the CDM, which dictate the evolution of damage in the laminate.

\section{TOWARD INTEGRATED COMPUTATIONAL MODELING OF MULTIFUNCTIONAL COMPOSITES}

Integrated computational materials engineering is an emerging discipline that aims to integrate

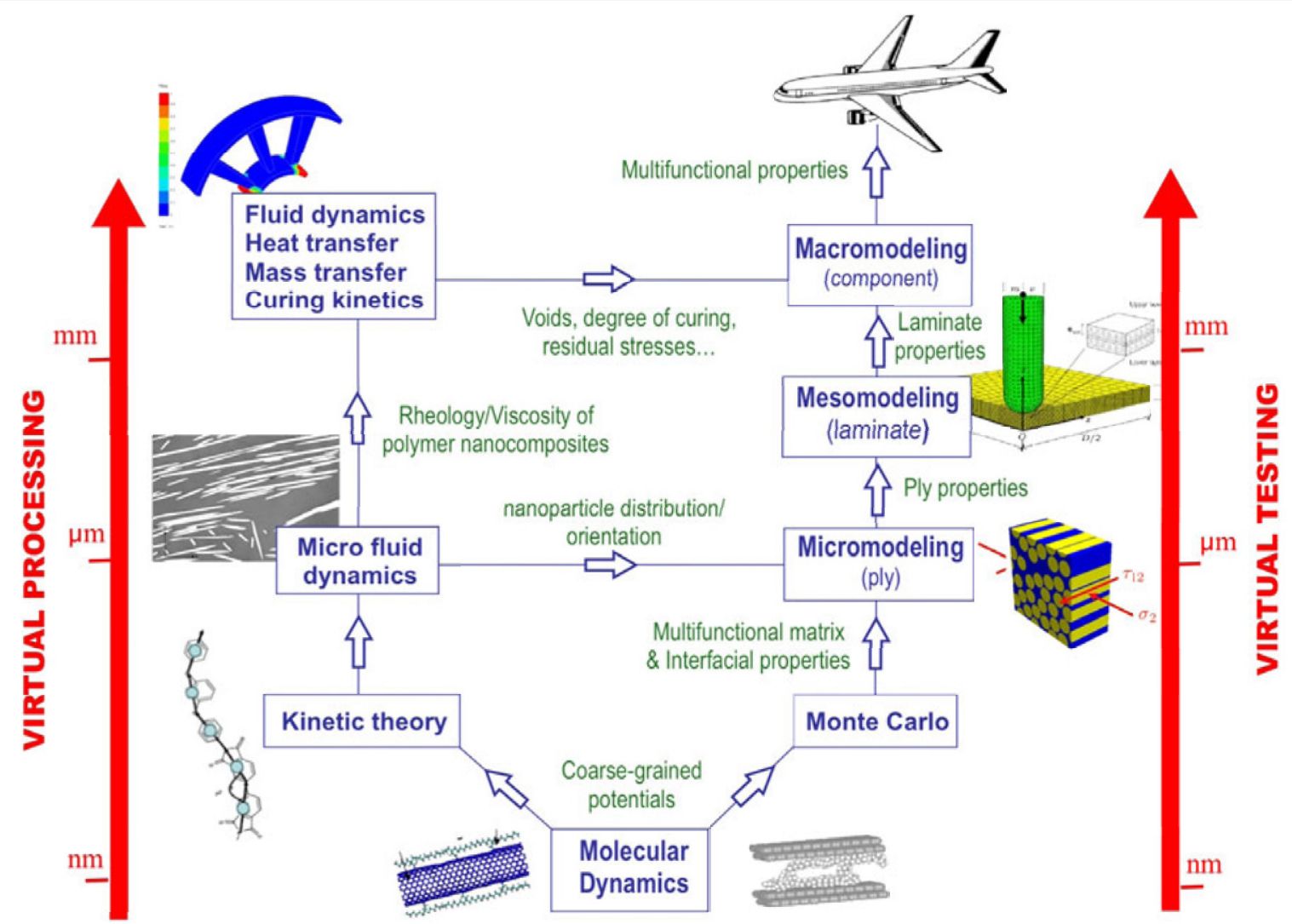

Fig. 10. Roadmap for integrated computational engineering of multifunctional FRP. The right-hand column shows the simulation strategy for virtual testing of structural and functional properties, whereas the left-hand column shows the ladder for virtual processing (from Ref. ${ }^{7}$ ). 
computational materials science tools into a holistic system that can accelerate materials development, transform the engineering design optimization process, and unify design and manufacturing. ${ }^{50,51}$ FRP are also included in this goal, and the results presented above demonstrate the feasibility of virtual mechanical testing of composites in the near future. Future developments and challenges in the area of multiscale modeling of FRP are likely to be found with the incorporation of multifunctional properties (thermal and electrical conductivity, electromagnetic shielding, fire resistance, etc.) and processing in the simulation strategy, leading to the development of a tool for integrated computational modeling of multifunctional composites. 8,52 Thus, the multiscale modeling scheme for virtual testing depicted in Fig. 5 has to be enlarged to incorporate functional properties as well as processing and the roadmap for integrated computational engineering of multifunctional composites is presented in Fig. 10.

The simulation cascade for virtual simulation of structural and functional properties is found in the right-hand column in Fig. 10. Starting at the $\mathrm{nm}$ scale, the mechanical and functional properties of polymers can be computed by means of molecular dynamics, which determine the time evolution of a set of atoms under the effect of external actions (stress, temperature, and electrical field) as well as of the interaction forces among them. Molecular dynamics simulations are limited in time and length scales, and an extension to larger volumes and longer times can be carried out by coarse-graining Monte Carlo methods or other techniques. ${ }^{53}$ The combination of these techniques can provide the material constants (electrical and thermal conductivity, gas permeability, thermal expansion coefficient, elastic constants, interface strength, electrical resistivity, etc.) used by continuum models to predict the overall composite behavior. The next steps in the multiscale simulation of functional properties should take advantage of the separation of length scales among individual plies, laminates, and components, and they follow the scheme developed to compute the structural properties.

Accurate prediction of the macroscopic properties also needs precise information about the structure of the material at the microscopic and macroscopic level. For instance, the behavior of the polymer nanocomposites used to infiltrate fiber preforms depends on the orientation and spatial distribution of the nanoreinforcements, whereas voids and thermal residual stresses generated during matrix infiltration and curing to manufacture the component are also critical. Thus, complete virtual testing is not possible without a virtual processing strategy. Simulation of processing is presented schematically in the left-hand column of Fig. 10. The initial step is also based on molecular dynamics simulations to determine the curing degree and/or molecular arrangement, as well as the interface energies associated with the presence of nanoparticles. These models also provide coarse-grained potentials to be used in the kinetic theory in which the enormous number of internal degrees of freedom of the polymer chain is reduced, leading to a simpler, beadstring description of the chain. This approximation can be coupled with continuum fluid dynamics to simulate rheological properties of the polymer and/ or of the nanocomposite. The next step involves the simulation of the infiltration process to manufacture components, but it should be noticed that the complete simulation of processing is a daunting task. It has to take into account mold filling, resin flow through the stack of fiber fabrics as well as within each fiber bundle, generation and transfer of heat due to the chemical reactions generated during curing, and the effect of the consolidation pressure. Moreover, these problems are coupled because the heat generated by chemical reactions accelerates the cross linking of the polymer network, dramatically increasing the resin viscosity until the gel point is reached while the consolidation pressure deforms the fiber fabric and changes its permeability. Thus, although significant progress has been attained in this area, ${ }^{54-56}$ a unified multiscale framework for virtual composite processing (equivalent to the one presented here for virtual testing) is the next challenge in developing an integrated design strategy for composites, so FRP components can be designed, tested, and optimized in silico before they are actually manufactured.

\section{ACKNOWLEDGEMENTS}

This investigation was supported by the Ministerio de Ciencia e Innovación of Spain through grant MAT2009-14396, by the Comunidad de Madrid through the program ESTRUMAT (S2009/MAT1585 ), by the research project DEFCOM (Era-Net MATERA, EU, 6th FP), and by the European Community's Seventh Framework Programme FP7/20072013 under Grant agreement 213371 (MAAXIMUS, www.maaximus.eu). In addition, the authors want to acknowledge the support of Airbus, Astrium, Abengoa Research, Gamesa, Aernnova, Aciturri, and Airbus Military through various industrial projects.

\section{REFERENCES}

1. M. Elices, eds., Structural Biological Materials (New York: Elsevier Science Ltd., 2000).

2. A. Gautieri, S. Vesentini, A. Redaelli, and M.J. Buehler, Nano Lett. 11, 757 (2011).

3. K. Tai, M. Dao, S. Suresh, A. Palazoglu, and C. Ortiz, Nat. Mater. 6, 454 (2007).

4. H.D. Espinosa, A.L. Juster, F.J. Latourte, O.Y. Loh, D. Gregoire, and P.D. Zavattieri, Nat. Comm. 2 (2011)

5 M. Elices, G.V. Guinea, G.R. Plaza, C. Karatzas, C. Riekel, F. Agullo-Rueda, R. Daza, and J. Perez-Rigueiro, Macromolecules 44, 1166 (2011).

6. H.D. Espinosa, T. Filleter, and M. Naraghi, Adv. Mater. 24, 2805 (2012).

7. J. LLorca, C. González, J.M. Molina-Aldareguía, J. Segurado, R. Seltzer, F. Sket, M. Rodríguez, S. Sádaba, R. Muñoz, and L.P. Canal, Adv. Mater. 23, 5130 (2011). 
8. L.P. Canal, C. González, J. Segurado, and J. Llorca, Comp. Sci. Technol. 72, 1223 (2012).

9. C. González and J. Llorca, Comp. Sci. Technol. 67, 2795 (2007).

10. B. Budiansky and N.A. Fleck, Appl. Mech. Rev. 47, S246 (1994).

11. F. Sket, R. Seltzer, J.M. Molina-Aldareguía, C. González, and J. Llorca, Comp. Sci. Technol. 72, 350 (2012).

12. B. Cox and Q. Yang, Science 314, 1102 (2006).

13. MIL-HDBK-17-1F, Composite Materials Handbook, Vol. 1-Polymer Matrix Composites, Guidelines for Characterization of Structural Materials, 2002.

14. M. Rodríguez, J.M. Molina-Aldareguía, C. González, and J. Llorca, Acta Mater. 60, 3953 (2012).

15. J.M. Molina-Aldareguía, M. Rodríguez, C. González, and J. Llorca, Philos. Mag. 91, 1293 (2011).

16. M. Rodriguez, J.M. Molina-Aldareguía, C. González, and J. Llorca, Comp. Sci. Technol. 72, 1924 (2012).

17. T.J. Vogler, S.-Y. Hsu, and S. Kyriakides, Int. J. Solids Struct. 37, 1765 (2000).

18. E. Totry, C. González, and J. Llorca, Comp. Sci. Technol. 68, $3128(2008)$.

19. E. Totry, C. González, and J. Llorca, Comp. Sci. Technol. 68, 829 (2008)

20. L.P. Canal, J. Segurado, and J. Llorca, Int. J. Solids Struct. 46,2265 (2009).

21. E. Totry, J.M. Molina-Aldareguía, C. González, and J. Llorca, Comp. Sci. Technol. 70, 970 (2010).

22. E. Totry, C. González, J. Llorca, and J. Molina-Aldareguía, Int. J. Fract. 158, 197 (2009).

23. T.J. Vaughan and C.T. McCarthy, Comp. Sci. Technol. 71, $388(2011)$.

24. M. Romanowicz, Comput. Mater. Sci. 51, 7 (2012)

25. V. Smilauer, C.G. Hoover, Z.P. Bazant, F.C. Caner, A.M. Waas, and K.W. Shahwan, Eng. Fract. Mech. 78, 901 (2011).

26. P.P. Camanho and C.G. Dávila, Mixed-Mode Decohesion Finite Elements for the Simulation of Delamination in Composite Materials, NASA/TM-2002-211737, 2002.

27. J. Segurado and J. Llorca, Int. J. Solids Struct. 41, 2977 (2004).

28. ASTM, Test Method D6671-01 (West Conshohocken, PA: American Society for Testing and Materials, 2002).

29. A. Puck and H. Schürmann, Comp. Sci. Technol. 62, 1633 (2002).

30. C.G. Dávila, P.P. Camanho, and C.A. Rose, J. Comp. Mater. $39,323(2005)$

31. S.T. Pinho, L. Iannucci, and P. Robinson, Composites A 37, $63(2006)$

32. A.S. Kaddour, M.J. Hinton, and P.D. Soden, Comp. Sci. Technol. 64, 449 (2004).

33. P.P. Camanho, P. Maimí, and C.G. Dávila, Comp. Sci. Technol. 67, 2715 (2007).
34. S.T. Pinho, P. Robinson, and L. Iannucci, Comp. Sci. Technol. 66, 2069 (2006).

35. S.R. Hallet and M.R. Wisnom, J. Comp. Mater. 40, 1229 (2006).

36. W.G. Jiang, S.R. Hallet, and M.R. Wisnom, Int. J. Numer. Methods Eng. 69, 1982 (2007).

37. S.R. Hallet, W.G. Jiang, B. Khan, and M.R. Wisnom, Comp. Sci. Technol. 68, 80 (2008).

38. C. Bouver, B. Castanié, M. Bizeul, and J.-J. Barrau, Int. J. Solids Struct. 46, 2809 (2009).

39. E.V. Iarve, M.R. Gurvich, D.H. Mollenhauer, C.A. Rose, and C.G. Dávila, Int. J. Numer. Methods Eng. 88, 749 (2011).

40. X.J. Fang, Q.D. Yang, B.N. Cox, and Z.Q. Zhou, Int. J. Numer. Methods Eng. 88, 841 (2011).

41. P. Ladevèze and G. Lubineau, Comp. Sci. Technol. 61, 2149 (2001).

42. P. Maimí, P.P. Camanho, J.A. Mayugo, and C.G. Dávila, Mech. Mater. 39, 897 (2007).

43. P. Maimí, P.P. Camanho, J.A. Mayugo, and C.G. Dávila, Mech. Mater. 39, 909 (2007)

44. C.S. Lopes, P.P. Camanho, Z. Gürdal, and B.F. Tatting, Int. J. Solids Struct. 44, 8493 (2007).

45. E. Arévalo, C. González, F. Gálvez, and J. LLorca, Proc. 23rd Int. Symp. Ballistics, ed. F. González and V. Sánchez-Gá lvez (Madrid, Spain: Universidad Politecnica de Madrid, 2007), pp. 1123-1132.

46. C.S. Lopes, P.P. Camanho, Z. Gürdal, P. Maimí, and E.V. González, Comp. Sci. Technol. 69, 937 (2009).

47. E.V. González, P. Maimí, P.P. Camanho, C.S. Lopes, and N. Blanco, Comp. Sci. Technol. 71, 805 (2011).

48. C.S. Lopes, O. Seresta, Z. Gürdal, P.P. Camanho, and B. Thuis, Comp. Sci. Technol. 69, 926 (2009).

49. T.A. Sebaey, E.V. González, C.S. Lopes, N. Blanco, and J. Costa, Comp. Struct. 95, 569 (2013).

50. National Research Council of the U.S. National Academies, Integrated Computational Materials Engineering (Washington, DC: The National Academy Press, 2008).

51. National Science and Technology Council, Materials Genome Initiative for Global Competitiveness (Washington, DC: The National Academy Press, 2011).

52. J. LLorca and C. González, 1st World Congress on Integrated Computational Materials Engineering (Warrendale, PA: TMS, 2011), pp. 121-127.

53. Q.H. Zeng, A.B. Yu, and G.Q. Lu, Prog. Pol. Sci. 33, 191 (2008).

54. S. Lopatnikov, P. Simacek, J. Gillespie Jr., and S.G. Advani, Model. Simul. Mater. Sci. Eng. 12, S191 (2004).

55. F. Trochu, E. Ruiz, V. Achim, and S. Soukane, Composites A $37,890(2006)$.

56. S.G. Advani, Int. J. Mater. Form. 2, 39 (2009). 